\title{
In vivo toxicological evaluation of graphene oxide nanoplatelets for clinical application
}

This article was published in the following Dove Press journal:

International Journal of Nanomedicine

\author{
Mohammad Amrollahi- \\ Sharifabadi' \\ Mohammad Kazem Koohi' \\ Ehsan Zayerzadeh ${ }^{2}$ \\ Mohammad Hassan \\ Hablolvarid $^{3}$ \\ Jalal Hassan' \\ Alexander M Seifalian ${ }^{4}$ \\ 'Department of Basic Sciences, \\ Faculty of Veterinary Medicine, \\ University of Tehran, Tehran, Iran; \\ ${ }^{2}$ Department of Biology, Faculty \\ of Food Industry and Agriculture, \\ Standard Research Institute, Karaj, \\ Iran; ${ }^{3}$ Department of Pathology, Razi \\ Vaccine and Serum Research Institute, \\ Agricultural Research, Education and \\ Extension Organization (AREEO), \\ Karaj, Iran; ${ }^{4}$ NanoRegMed Ltd, \\ Nanotechnology and Regenerative \\ Medicine Commercialization Centre, \\ The London BioScience Innovation \\ Centre, London, UK
}

Background: Graphene is considered as a wonder material; it is the strongest material on the planet, super-elastic, and conductive. Its application in biomedicine is huge, with a multibilliondollar industry, and will revolutionize the diagnostic and treatment of diseases. However, its safety and potential toxicity is the main challenge.

Methods: This study assessed the potential toxicity of graphene oxide nanoplatelets (GONs) in an in vivo animal model using systemic, hematological, biochemical, and histopathological examinations. Normal saline (control group) or GONs (3-6 layers, lateral dimension $=5-10 \mu \mathrm{m}$, and thickness $=0.8-2 \mathrm{~nm}$ ) at dose rate of 50,150 , or $500 \mathrm{mg} / \mathrm{kg}$ were intraperitoneally injected into adult male Wistar rats ( $n=5)$ every 48 hours during 1 week to receive each animal a total of four doses. The animals were allowed 2 weeks to recover after the last dosing. Then, animals were killed and the blood was collected for hematological and biochemical analysis. The organs including the liver, kidney, spleen, lung, intestine, brain, and heart were harvested for histopathological evaluations.

Results: The results showed GONs prevented body weight gain in animals after 21 days, treated at $500 \mathrm{mg} / \mathrm{kg}$, but not in the animals treated at 150 or $50 \mathrm{mg} / \mathrm{kg}$ GONs. The biochemical analysis showed a significant increase in total bilirubin, with a significant decrease in triglycerides and high-density lipoprotein in animals treated at $500 \mathrm{mg} / \mathrm{kg}$. Nonetheless, other hematological and biochemical parameters remained statistically insignificant in all GONs treated animals. The most common histopathological findings in the visceral organs were granulomatous reaction with giant cell formation and accumulation of GONs in capsular regions. Also, small foci of neuronal degeneration and necrosis were the most outstanding findings in the brain, including the cerebellum.

Conclusion: In conclusion, this study shows that GONs without functionalization are toxic. The future study is a comparison of the functionalized with non-functionalized GONs.

Keywords: graphene oxide, nanoplatelets, toxicity, preclinical, rat, histopathology, nanotechnology

\section{Introduction}

Graphene is a carbon-based nanomaterial that is derived from crystalline graphite. ${ }^{1}$ Graphene is considered a wonder material; it is the strongest material on the planet, super-elastic, and conductive. It has huge applications in medicine, as well as nonmedical fields. It is a multibillion dollar industry and will revolutionize our life in the future. Medical applications include drug and gene deliveries, cancer treatment, and development of organs or biomarkers. ${ }^{2}$ The 2-dimensional (2D) nanostructure of graphene is composed of a single layer of atomic carbons which are organized hexagonally in honeycomb-like networks. ${ }^{3}$ Generally speaking, there is a large family of graphene nanomaterials (GNMs) that can be fabricated through various methodologies. ${ }^{4-7}$ 
Therefore, there are morphologically different types of GNMs, including graphene nano-sheets, nanoplatelets, nano-ribbons, nano-onions, nano-quantum dots, and nanoshells, just to name a few. ${ }^{8-11}$ Moreover, GNMs can be used either in their intact, pure carbonic form, which is known as pristine graphene, or they can be produced as a functionalized form by subjecting to different chemical or biochemical modifications. ${ }^{12-14}$ Oxidation is among the common modification techniques that resulted in graphene oxide (GO). GO has attracted a great deal of attention as a promising nanomaterial in various biomedical applications. ${ }^{15,16}$

The safety and biocompatibility of GO has been a subject of intense research in the scientific community. The reports have been controversial, some reported that $\mathrm{GO}$ is nontoxic, even in a high dose of $200 \mu \mathrm{g} / \mathrm{mL}$ after 24 hours of exposure to cells lines, ${ }^{17,18}$ while others reported that GO interacted with DNA and induced mutagenesis in the MDA-MB-231 human breast cancer cells. ${ }^{19}$ In fact, GO, even at the low dose of $10 \mu \mathrm{g} / \mathrm{mL}$, altered gene expression patterns and caused cell apoptosis. Recent studies showed that intravenous injections of $\mathrm{GO}$ at $4 \mathrm{mg} / \mathrm{kg}$ for five consecutive days caused mutagenesis in mice..$^{19,20}$

A study investigated the biocompatibility and the distribution of GO (single layer, thickness $=1.0 \mathrm{~nm}$, lateral dimension $=10-800 \mathrm{~nm}$ ) in mice following intravenous administration. It showed that GO remained in the blood circulation for a long time, and predominantly accumulated in the lungs. The researchers observed significant pathological changes, including inflammatory cell infiltration, pulmonary edema, and granulomatous reaction at the animals dosed at $10 \mathrm{mg} / \mathrm{kg} \mathrm{GO}$ after 14 days. However, they did not observe pathological changes in other organs, including the liver, spleen, and kidney in animals treated with $10 \mathrm{mg} / \mathrm{kg}$ GO after 14 days. Moreover, GO showed good biocompatibility with red blood cells in their study. ${ }^{21}$ Accordingly, the potential toxicity and the biocompatibility of GO remain controversial. In fact, parameters including morphology, ${ }^{22,23}$ size (lateral dimension, thickness, and number of layers), ${ }^{24,25}$ concentration, ${ }^{17,23}$ exposure time, ${ }^{26}$ and surface activity (area, functional group) ${ }^{27}$ can substantially influence the potential toxicity and biocompatibility of GO and, thus, can convert it from a nontoxic to a highly toxic chemical for living organisms. Considering the aforementioned parameters, there are numerous types of GO with various properties that need to be evaluated for potential toxicities. In toxicological evaluations, it is of paramount importance to provide the sufficient data on the characterization of GO, especially the morphology, size, and surface activity, because, otherwise, this would lead to inconclusive, sometimes contradictory results toward safety profiling of these chemicals. This, in turn, will postpone the promising applications of GO in the biomedical fields. The scarcity of in vivo studies on the toxicity of GO while addressing the complete characteristics of GO was noticed in the most recent literature. ${ }^{28}$ We have been working on physiochemical properties and functionalization of $\mathrm{GO}^{29}$ and its medical as well as marine applications, the latter as anti-biofouling paint. For medical application, the work is based on the development of organs using a functionalized GO-based nanocomposite scaffold and stem cells technology. Therefore, the toxicology of GO is important and required by the FDA and other regulatory bodies for translation to humans. However, due to its controversial reports on its toxicity, further in vivo studies are crucial to better understand the toxicological effects of the nanoparticles. Our work is based on GO as a nanoplatelet morphology having 3-6 layers, with lateral dimensions of 5-10 $\mu \mathrm{m}$, and a thickness of $0.8-2 \mathrm{~nm}$. Thus, we embarked on an in vivo toxicological investigation of this special characteristic GO nanoplatelet. The study used Wistar rats as an in vivo animal model. In order to inspect the potential hematotoxicity of GO, major hematological indices were evaluated in the whole blood of animals after exposing to GO. Moreover, we assessed whether the GO show significant changes in the serum levels of biomarkers exploring the potential target organ toxicity of GO through circulating biomarkers. The effects of GO on the serum levels of total protein, lipids, and electrolytes were evaluated to search for any potential interaction of GO with these blood parameters. Finally, the histopathological examinations of major organs of the animals including the liver, kidney, spleen, lung, intestine, brain, and heart were performed to explore the potential dispositional and accumulating fate of GO inside the body, and also the potential specific toxicities of GO toward these organs. To the best of our knowledge, this is the first report on the in vivo toxicological evaluation of this characterized GO in the current literature using mentioned examinations as toxicity endpoints.

\section{Materials and methods GO and characterization}

GO (CAS No of 7732-18-5; carbon purity of 99\%) was obtained from the US Research Nanomaterials, Inc. (Houston, TX). Characterization of GO was done using X-ray diffraction (XRD) analysis, Raman spectroscopy, field-emission scanning electron microscopy (FESEM), and transmission electron microscopy (TEM) techniques. XRD measurement was performed on a Philips X'Pert MPD Diffractometer (UK) 
using $\mathrm{Cu} \mathrm{K} \alpha$ radiation $\left(\lambda=1.5418 \mathrm{~A}^{\circ}\right)$ at the voltage of $40 \mathrm{kV}$ and the current of $15 \mathrm{~mA}$ by scanning in a $2 \theta$ range from $0^{\circ}$ to $80^{\circ}$. The Raman spectroscopy spectrum was recorded by an Almega Thermo Nicolet Dispersive Raman Spectrometer (Germany) using laser light $(\lambda=532 \mathrm{~nm})$ and in the spectral range of $500-3,000 \mathrm{~cm}^{-1}$. The surface morphology of GO was inspected utilizing FESEM (Sigma, Carl Zeiss, Germany) equipped with an Everhart-Thornley detector (SE2) at the accelerating voltage of $15 \mathrm{kV}$ and working distance of $8.7 \mathrm{~mm}$. TEM (Hitachi S4160, Tokyo, Japan) was used at the accelerating voltage of $30 \mathrm{kV}$ to study the size and morphology of GO. The Brunauer-Emmett-Teller (BET) surface area of GO was acquired through a NOVA 2000e surface analyzer (Quantachrome Instruments, USA).

\section{In vivo animal study}

Twenty adult male Wistar rats ( $8-12$ weeks age, body weight of 150-200 g) were obtained from Pasture Institute (Tehran, Iran). The animals were housed in polyethylene cages and maintained under the controlled temperature and 12 hours light/12 hours dark conditions for 1 week before the start of the experiment. They were allowed ad libitum access to the standard pellet and tap water. Animals received humane care, and all the experiments were performed in accordance with the Guidelines of the Institutional Animal Care and Use Committee and were approved by the Animal Ethics Committee of the Faculty of Veterinary Medicine, University of Tehran, Iran (approval No of 7506023.6.17).

Twenty rats were randomly divided into four groups of five animals per group (Table 1). Group I was assigned as a vehicle control and received normal saline $0.9 \%$ by intraperitoneal injection $(5 \mathrm{~mL} / \mathrm{kg})$. Groups II-IV were received four doses of GO at 50,150, or $500 \mathrm{mg} / \mathrm{kg}$ every 48 hours during 1 week.

The selected dose levels of GO were based on our range-finding study. Moreover, our dose selection was in agreement with a recently published study that conducted a comprehensive preclinical safety assessment of a GO pharmaceutical formulation by following regulatory guidelines and performing with good laboratory practice..$^{30}$
Two weeks after the last dosing, the animals euthanized and blood and organ samples harvested for further toxicological evaluations. The weights of animals were determined before dosing animals with $\mathrm{GO}$ and at the final of the experimental period.

\section{Preparation of GO}

For each animal, appropriate milligrams of $\mathrm{GO}$ were weighed and transferred into the sterile tubes which previously contained normal saline $0.9 \%$ solution. Then, the suspensions of nanoparticles were prepared by vortexing the tubes for 10 minutes. GO was homogenously dispersed in normal saline $0.9 \%$ solution without producing any agglomerations, and the homogeneity of every dosage was maintained before injecting intraperitoneally into the animals by gentle stirring. All doses of homogenous GO suspensions were prepared freshly and warmed at $37^{\circ} \mathrm{C}$ each time before the injection.

\section{Hematological and biochemical measurements}

Rats were anesthetized with diethyl-ether, and blood samples were collected through the cardiac puncture technique and were divided into two aliquots. The first one was put into BD Vacutainer ${ }^{\mathbb{B}}$ blood collection tubes containing $\mathrm{K}_{3}$-EDTA (Beckton \& Dickton, Franklin Lakes, NJ, USA) for hematological analysis, and the second one was put into plain tubes in order to prepare the serum samples for biochemical analysis. Serum samples were prepared by centrifugation at 3,000 g for 15 minutes.

Hematological parameters in the whole blood included hemoglobin ( $\mathrm{Hgb})$, haematocrit (Hct), white blood cell (WBC) count, red blood cell (RBC) count, mean corpuscular hemoglobin $(\mathrm{MCH})$, mean corpuscular volume (MCV), mean corpuscular hemoglobin concentration (MCHC), and platelet count (PLT). These parameters were analyzed by a hematology autoanalyzer Sysmex Kx-21n (Sysmex Corporation, Japan). The biochemical parameters in the serum samples included blood urea nitrogen (BUN), creatinine (Crea), aspartate aminotransferase (AST), alanine

Table I Animal groups and GONs injections

\begin{tabular}{lllll}
\hline Group & Substance & $\begin{array}{l}\text { Number } \\
\text { of animals }\end{array}$ & $\begin{array}{l}\text { Number of } \\
\text { i.p. injections }\end{array}$ & $\begin{array}{l}\text { Interval between } \\
\text { each injection }\end{array}$ \\
\hline I & C (NS) & 5 & 4 & 48 hours \\
II & GONs in NS (50 mg/kg) & 5 & 4 & 48 hours \\
III & GONs in NS (I50 mg/kg) & 5 & 4 & 48 hours \\
IV & GONs in NS (500 mg/kg) & 5 & 4 & 48 hours \\
\hline
\end{tabular}

Abbreviations: GONs, graphene oxide nanoplatelets; C, control; NS, normal saline; i.p., intraperitoneal. 
aminotransferase (ALT), alkaline phosphatase (ALP), gamma-glutamyltransferase (GGT), total bilirubin (TB), direct bilirubin (DB), creatine phosphokinase (CPK), total protein (TP), triglyceride (TG), cholesterol (CHO), high density lipoprotein (HDL), and low density lipoprotein (LDL). They analyzed by a biochemical autoanalyzer BT3000 (BioTechnica, Italy) with standard diagnostic kits (Pars Azmoun Co., Iran). Serum levels of creatine kinase-MB (CK-MB) were measured on the basis of chemiluminescent immunoassay (CLIA) method by a LIAISON ${ }^{\circledR}$ analyzer (DiaSorin, Inc. Germany). Serum electrolytes included sodium $\left(\mathrm{Na}^{+}\right)$, potassium $\left(\mathrm{K}^{+}\right)$, and calcium $\left(\mathrm{Ca}^{2+}\right)$ were determined by an electrolyte analyzer equipped with an ion selective electrode (Caretium Medical Instruments Co., China).

\section{Histopathological examinations}

The animals were killed by cervical dislocation after blood collection and immediately underwent an autopsy. The internal organs of animals, including the liver, kidney, spleen, lung, intestine, brain, and heart, were harvested and washed with normal saline and then fixed for 48 hours in a $10 \%$ neutral buffered formalin at room temperature. Organs were dehydrated in a graded series of ethanol and xylene and embedded in paraffin and sectioned into slices of $5 \mu \mathrm{m}$ thickness provided by a rotary microtome. Then, the blocks were deparaffinized and stained with hematoxylin and eosin (H\&E). Microscopic evaluations were performed by using a bright-field microscope (Nikon Eclipse 80i, Japan).

\section{Data analysis}

The results are presented as means and SD. The one-way ANOVA test with post hoc Bonferroni analysis was used for comparing the groups. A $P$-value $<0.05$ was considered as statistically significant. The data analysis was performed by GraphPad Prism Version 5.04 (GraphPad Software, Inc., La Jolla, CA, USA).

\section{Results \\ The characterization of GO}

Results of XRD analysis and Raman spectroscopy are shown in Figures $1 \mathrm{~A}$ and $\mathrm{B}$, respectively. XRD analysis of GO samples showed the featured sharp peak at $2 \theta=\sim 11^{\circ}$ indicated structural properties of GO. The Raman spectrum of GO showed a D band at $1,348 \mathrm{~cm}^{-1}$, a G band at $1,585 \mathrm{~cm}^{-1}$, and $2 \mathrm{D}$ band at $2,700 \mathrm{~cm}^{-1}$, as GO known peaks. Representative FESEM and TEM images of GO are shown in Figures $1 \mathrm{C}$
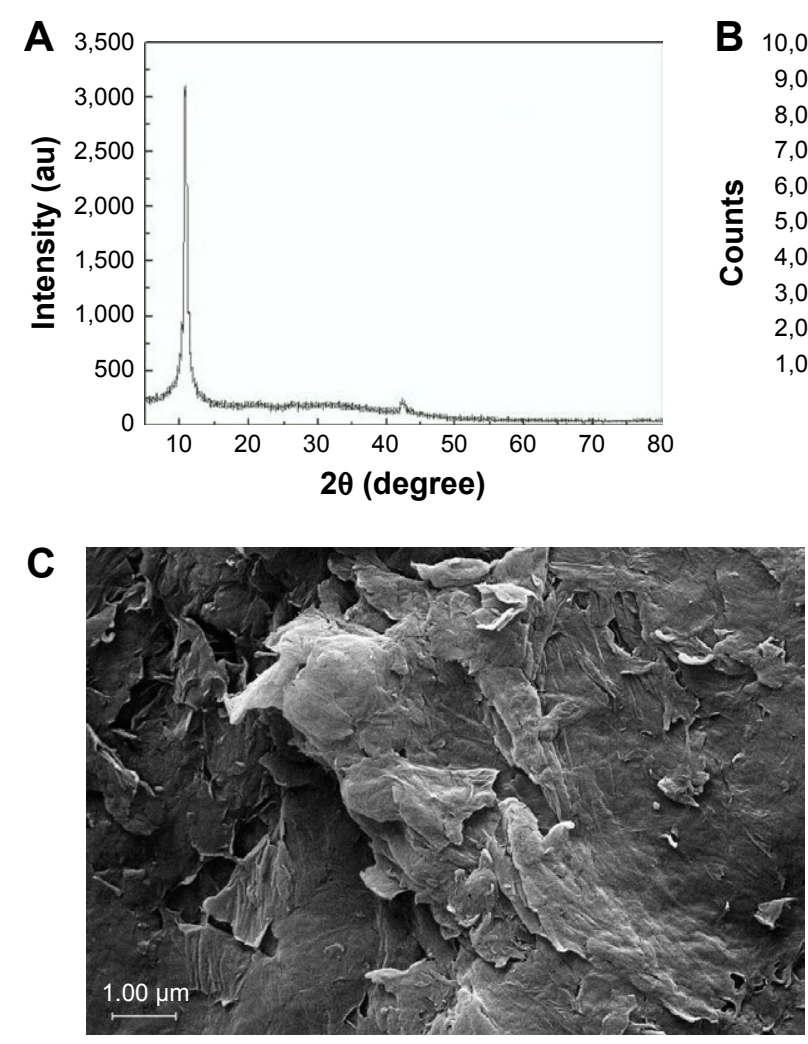

Figure I Characteristics of GONs. (A) XRD analysis. (B) Raman spectrum. (D) Representative transmission electron microscopic micrograph of GONs.

Abbreviations: GONs, graphene oxide nanoplatelets; XRD, X-ray diffraction.
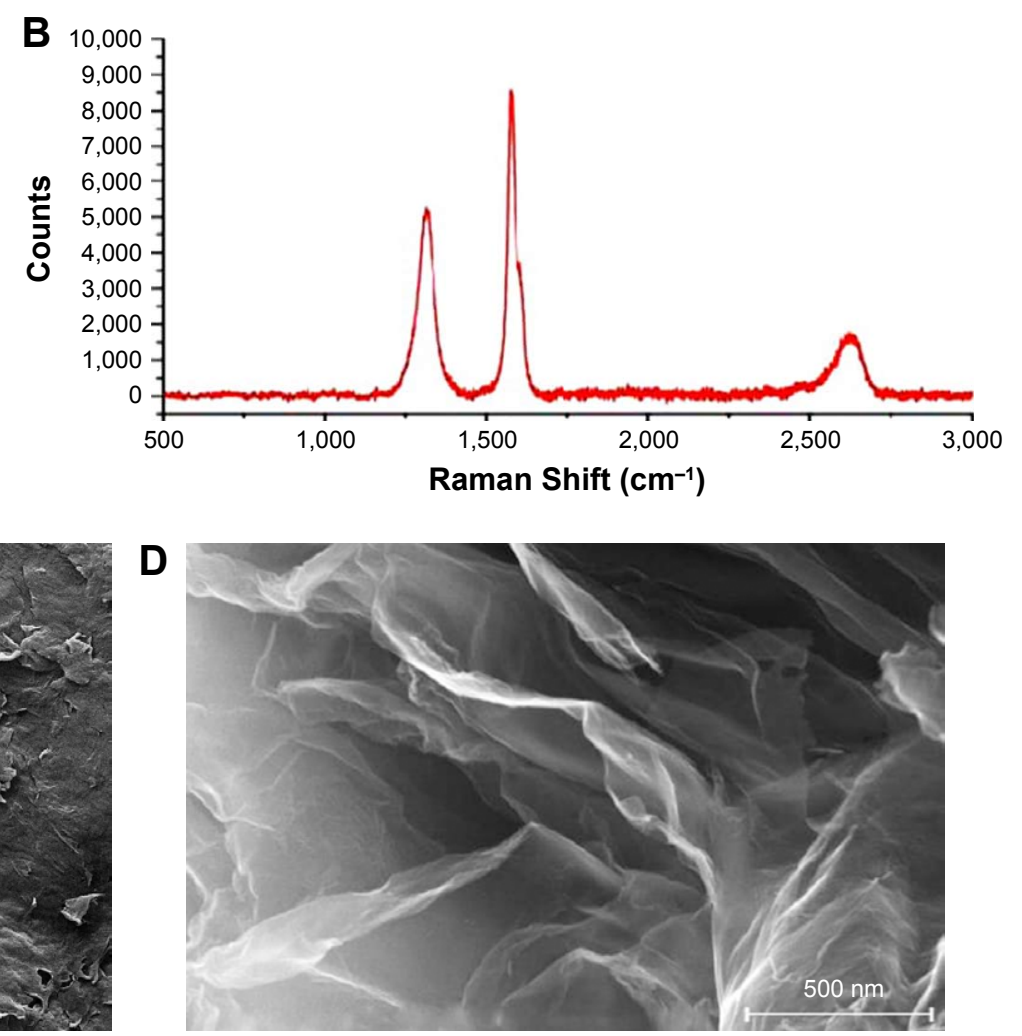

(C) Representative field-emission scanning electron microscopic micrograph of GONs. 
and D, respectively. The morphology of GO was generally nanoplatelets with the average number of layers of 3-6. The thickness of nanoplatelets was $0.8-2 \mathrm{~nm}$, and the lateral dimension was $5-10 \mu \mathrm{m}$. The specific surface area of GO was $360 \mathrm{~m}^{2} / \mathrm{g}$, as determined by BET technique.

\section{Effects of graphene oxide nanoplatelets (GONs) on body weight changes, hematological, and biochemical parameters}

Changes in the body weights of animals are presented in Figure 2. Rats in the control group showed a statistically significant increase in body weight at the end of the experiment compared with the baseline. Also, we found a significant increase in the body weights of rats receiving 50 and $150 \mathrm{mg} / \mathrm{kg}$ GONs at the final of the study period when compared with their pertinent baselines. However, the animals receiving $500 \mathrm{mg} / \mathrm{kg}$ GONs did not display a significant body weight increase at the end of the study period when compared with the baseline.

The results of analyzed parameters in the whole blood and the serum are presented in Table 2. The levels of TB increased significantly in rats receiving $500 \mathrm{mg} / \mathrm{kg}$ GONs when compared with control, but not in the rats receiving 50 or $150 \mathrm{mg} / \mathrm{kg}$ GONs. GONs caused a significant decrease in $\mathrm{TG}$ and $\mathrm{HDL}$ in rats receiving $500 \mathrm{mg} / \mathrm{kg}$ GONs when compared with control. However, there were no statistically

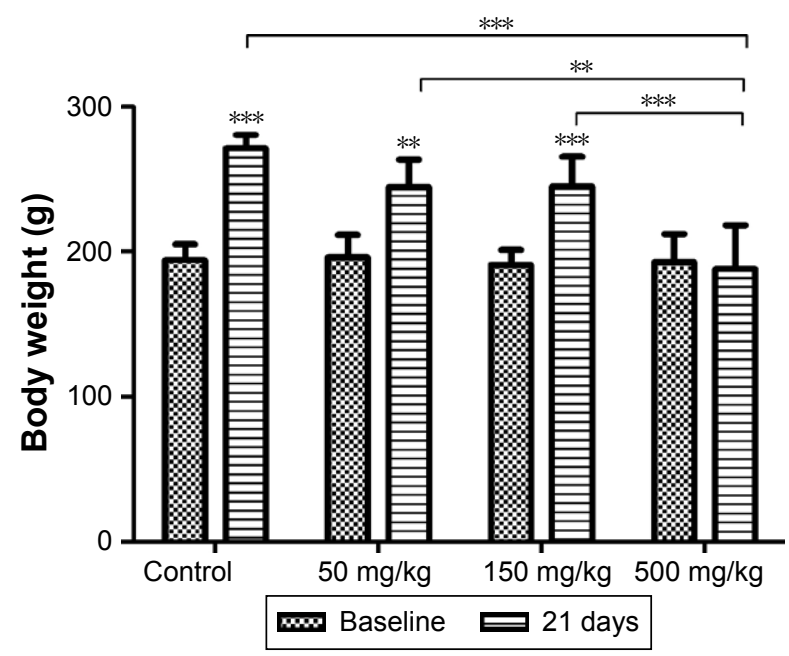

Figure 2 Changes in the body weights of the animals at the baseline and 21 days after receiving repeated doses of GONs via intraperitoneal injections.

Notes: Data are shown as mean \pm SD $(n=5)$. $* * P<0.01$, $* * * P<0.00$ I, significantly different when body weights of each group at 21 days were compared with the baseline. Asterisks above the lines indicated significant differences when comparing the body weights of each group at day 21 with the body weight of the $500 \mathrm{mg} / \mathrm{kg}$ group at day 21 .

Abbreviation: GONs, graphene oxide nanoplatelets. significant changes in TG and HDL in other GONs treated animals. Also, we did not find any significant changes in other analyzed parameters in the whole blood and the serum.

\section{Histopathological findings}

The histology of liver in the control group was normal, with no lesions (Figure 3A). Histopathological examination of the liver of rats receiving $50 \mathrm{mg} / \mathrm{kg}$ GONs revealed mild sinusoidal injury and hyperemia (Figure 3B). We observed a granulomatous reaction with some giant cells in the hepatic capsular regions of rats receiving $150 \mathrm{mg} / \mathrm{kg}$ GONs. Other histopathological changes in this group included perivascular infiltrations (Figure 3C). Massive foci accumulation of particles revealed in the hepatic capsular region of rats received $500 \mathrm{mg} / \mathrm{kg}$ GONs (Figure 3D).

No histopathological lesion in the kidney of control rats was observed (Figure 4A). In the kidney of rats receiving $50 \mathrm{mg} / \mathrm{kg} \mathrm{GONs}$, there were small foci of GONs accumulation at the capsular regions. Other histopathological changes in this group were included hyperemia, few foci of interstitial nephritis, and glomerular atrophy (Figure 4B). There was multifocal nephritis in the kidney of rats receiving $150 \mathrm{mg} / \mathrm{kg}$ GONs. Also, accumulated particles of GONs at the capsular regions of kidneys were noticed in this group (Figure 4C). Kidney sections in rats receiving $500 \mathrm{mg} / \mathrm{kg}$ GONs revealed a granulomatous reaction with giant cell formation in capsular regions, as a consequence of massive accumulation of GONs (Figure 4D).

Histology of the spleen was normal in the control group (Figure 5A). In the spleen sections of rats receiving $50 \mathrm{mg} / \mathrm{kg}$ GONs, we observed small foci of accumulated GONs particles and hemosiderosis (Figure 5B). There was capsular accumulation of particles in the spleen of rats receiving $150 \mathrm{mg} / \mathrm{kg}$ GONs (Figure 5C). Capsular thickening and accumulation of particles observed in rats receiving $500 \mathrm{mg} / \mathrm{kg}$ GONs were more noticeable than in the 150 or $50 \mathrm{mg} / \mathrm{kg}$ GONs treated groups (Figure 5D).

In the lung of rats receiving $50 \mathrm{mg} / \mathrm{kg} \mathrm{GONs}$, there was mild alveolar wall thickening. There were small foci of an inflammatory reaction with hemosiderosis in the lung of rats receiving $150 \mathrm{mg} / \mathrm{kg}$ GONs. In the lung of rats receiving $500 \mathrm{mg} / \mathrm{kg}$ GONs, we observed alveolar wall thickening, hyperemia, and hemosiderosis (Figure 6).

Examinations of intestinal sections revealed mesenteric thickening, along with accumulation of GONs and giant cells. These findings were more noticeable in rats receive $500 \mathrm{mg} / \mathrm{kg}$, in comparison with rats receiving 150 or $50 \mathrm{mg} / \mathrm{kg}$ GONs (Figure 7). 
Table 2 Effects of GONs on hematological and biochemical parameters ${ }^{\mathrm{a}}$ in rats after 21 days

\begin{tabular}{|c|c|c|c|c|}
\hline Parameters & $0 \mathrm{mg} / \mathrm{kg}$ & $50 \mathrm{mg} / \mathrm{kg}$ & 150 mg/kg & $500 \mathrm{mg} / \mathrm{kg}$ \\
\hline \multicolumn{5}{|l|}{ Blood } \\
\hline WBC $\left(10^{3} / \mu \mathrm{L}\right)$ & $12.10 \pm 4.39$ & $13.68 \pm 3.93$ & $18.24 \pm 4.17$ & $15.82 \pm 2.56$ \\
\hline $\operatorname{RBC}\left(10^{6} / \mu \mathrm{L}\right)$ & $8.53 \pm 0.92$ & $8.06 \pm 1.35$ & $8.16 \pm 0.99$ & $7.54 \pm 1.12$ \\
\hline Hgb (g/dL) & $17.54 \pm 1.54$ & $17.34 \pm 0.73$ & $17.02 \pm 1.57$ & $16.56 \pm 0.76$ \\
\hline Hct (\%) & $51.74 \pm 2.38$ & $52.18 \pm 2.02$ & $51.36 \pm 4.33$ & $50.66 \pm 2.06$ \\
\hline $\mathrm{MCV}(\mathrm{fL})$ & $61.74 \pm 2.58$ & $62.20 \pm 3.11$ & $60.98 \pm 2.34$ & $64.68 \pm 7.22$ \\
\hline $\mathrm{MCH}(\mathrm{pg})$ & $19.90 \pm 0.95$ & $19.64 \pm 2.09$ & $19.96 \pm 0.96$ & $20.68 \pm I .64$ \\
\hline $\mathrm{MCHC}(\mathrm{g} / \mathrm{dL})$ & $32.20 \pm 1.00$ & $31.70 \pm 4.43$ & $32.70 \pm 0.54$ & $31.20 \pm 1.36$ \\
\hline PLT $\left(10^{3} / \mu \mathrm{L}\right)$ & $623.00 \pm 240.10$ & $452.00 \pm 164.20$ & $807.00 \pm 95.16$ & $604.40 \pm 297.90$ \\
\hline \multicolumn{5}{|l|}{ Liver } \\
\hline ALT (U/L) & $76.00 \pm 19.53$ & $63.20 \pm 11.90$ & $67.00 \pm 17.99$ & $85.40 \pm 18.73$ \\
\hline AST (U/L) & $158.80 \pm 14.18$ & $|7| .60 \pm 2 \mid .42$ & $|55.80 \pm 2| .5 \mid$ & $183.20 \pm 35.95$ \\
\hline ALP (U/L) & $933.00 \pm 242.30$ & $993.80 \pm 169.30$ & $789.80 \pm 148.90$ & $1,005.00 \pm 188.60$ \\
\hline GGT (U/L) & $|2.82 \pm 5.6|$ & $\mid 1.00 \pm 2.21$ & $7.95 \pm 2.87$ & $7.99 \pm 2.52$ \\
\hline $\mathrm{DB}(\mathrm{mg} / \mathrm{dL})$ & $0.19 \pm 0.08$ & $0.25 \pm 0.19$ & $0.13 \pm 0.03$ & $0.13 \pm 0.05$ \\
\hline TB (mg/dL) & $0.43 \pm 0.16$ & $0.35 \pm 0.09$ & $0.27 \pm 0.11$ & $0.76 \pm 0.15^{* *}$ \\
\hline \multicolumn{5}{|l|}{ Kidney } \\
\hline BUN (mg/dL) & $33.90 \pm 4.15$ & $38.68 \pm 2.89$ & $38.72 \pm 19.16$ & $36.10 \pm 11.49$ \\
\hline Crea $(\mathrm{mg} / \mathrm{dL})$ & $0.57 \pm 0.07$ & $0.58 \pm 0.01$ & $0.53 \pm 0.03$ & $0.54 \pm 0.04$ \\
\hline \multicolumn{5}{|l|}{ Heart } \\
\hline CPK (U/L) & $830.00 \pm 171.60$ & $\mathrm{I}, 103.00 \pm 430.40$ & $\mathrm{I}, 023.00 \pm 157.30$ & $\mathrm{I}, 194.00 \pm 502.40$ \\
\hline CK-MB (ng/mL) & $2.02 \pm 0.65$ & $1.95 \pm 0.54$ & $1.92 \pm 0.83$ & $1.55 \pm 0.65$ \\
\hline \multicolumn{5}{|l|}{ Protein and lipid } \\
\hline TP (g/dL) & $6.06 \pm 0.20$ & $6.08 \pm 0.60$ & $6.12 \pm 0.26$ & $5.99 \pm 0.49$ \\
\hline TG (mg/dL) & $118.40 \pm 15.18$ & $136.40 \pm 15.24$ & $97.80 \pm 32.46$ & $54.90 \pm 27.35^{* *}$ \\
\hline $\mathrm{CHO}(\mathrm{mg} / \mathrm{dL})$ & $62.80 \pm 19.18$ & $63.60 \pm 11.59$ & $71.20 \pm 8.17$ & $69.80 \pm 13.55$ \\
\hline HDL (mg/dL) & $36.60 \pm 5.32$ & $31.40 \pm 5.13$ & $33.60 \pm 4.22$ & $26.90 \pm 3.98^{*}$ \\
\hline LDL (mg/dL) & $2.45 \pm 0.74$ & $1.88 \pm 0.97$ & $1.55 \pm 0.50$ & $3.21 \pm 0.7 \mathrm{I}$ \\
\hline \multicolumn{5}{|l|}{ Electrolyte } \\
\hline $\mathrm{Na}^{+}(\mathrm{mmol} / \mathrm{L})$ & $137.20 \pm 1.79$ & $|35.40 \pm 4.5|$ & $|34.60 \pm 2.4|$ & $135.20 \pm 1.64$ \\
\hline $\mathrm{K}^{+}(\mathrm{mmol} / \mathrm{L})$ & $4.88 \pm 0.92$ & $4.94 \pm 0.59$ & $4.86 \pm 0.77$ & $4.99 \pm 0.84$ \\
\hline $\mathrm{Ca}^{2+}(\mathrm{mg} / \mathrm{dL})$ & $9.53 \pm 0.58$ & $9.22 \pm 0.29$ & $9.04 \pm 0.62$ & $8.96 \pm 0.25$ \\
\hline
\end{tabular}

Notes: ${ }^{a}$ Each value represents the mean $\pm S D(n=5)$. $* P<0.05$, $* * P<0.01$, significantly different when compared with control.

Abbreviations: GONs, graphene oxide nanoplatelets; WBC, white blood cell count; RBC, red blood cell count; Hgb, hemoglobin; Hct, hematocrit; MCV, mean corpuscular volume; $\mathrm{MCH}$, mean corpuscular hemoglobin; MCHC, mean corpuscular hemoglobin concentration; PLT, platelet count; ALT, alanine aminotransferase; AST, aspartate aminotransferase; ALP, alkaline phosphatase; GGT, gamma-glutamyltransferase; DB, direct bilirubin; TB, total bilirubin; BUN, blood urea nitrogen; Crea, creatinine; CPK, creatine phosphokinase; CK-MB, creatine kinase-MB; TP, total protein; TG, triglyceride; CHO, cholesterol; HDL, high-density lipoprotein; LDL, low-density lipoprotein; Na+, sodium; $\mathrm{K}^{+}$, potassium; $\mathrm{Ca}^{2+}$, calcium.

Microscopic examinations of the brain sections displayed abnormal changes in neuronal tissues of all GONs treated groups in comparison with the control group. In fact, some of the neuronal cells of both cerebral and cerebellar cortices showed degeneration and necrosis. These changes were more noticeable in animals receiving $500 \mathrm{mg} / \mathrm{kg}$ GONs than in animals receiving 150 or $50 \mathrm{mg} / \mathrm{kg}$ GONs. In the cerebellar cortex of all GONs treated animals, we observed the distortion of cerebellar layers that were accompanied by different degrees of degenerated and necrotic neuronal cells (Figure 8). In particular, degenerated and necrotized Purkinje cells were most conspicuous. Architecture of Purkinje cells perturbed, their cytoplasm shrank, their nuclei disappeared. Also, we observed the loss of Purkinje cells in the Purkinje cell layer. These histopathological alterations were more severe in rats receiving $500 \mathrm{mg} / \mathrm{kg}$ GONs when compared with rats receiving either 150 or $50 \mathrm{mg} / \mathrm{kg}$ GONs. Also, we observed some degrees of hyperemia and hemorrhage in the cerebellar tissues of treated animals with GONs when compared with control. No morphological changes in meninges and white matter were noticed in any GONs treated groups. Histopathological examinations of hearts disclosed no morphological changes in all GONs treated animals, in comparison with control (data not shown).

\section{Discussion}

Studies on the safety assessment of GO in vivo animal models are still lacking. ${ }^{12,28}$ In this regard, there is an urgent need for more animal studies to clarify the systemic behaviors of these nanomaterials and their potential toxicities. 

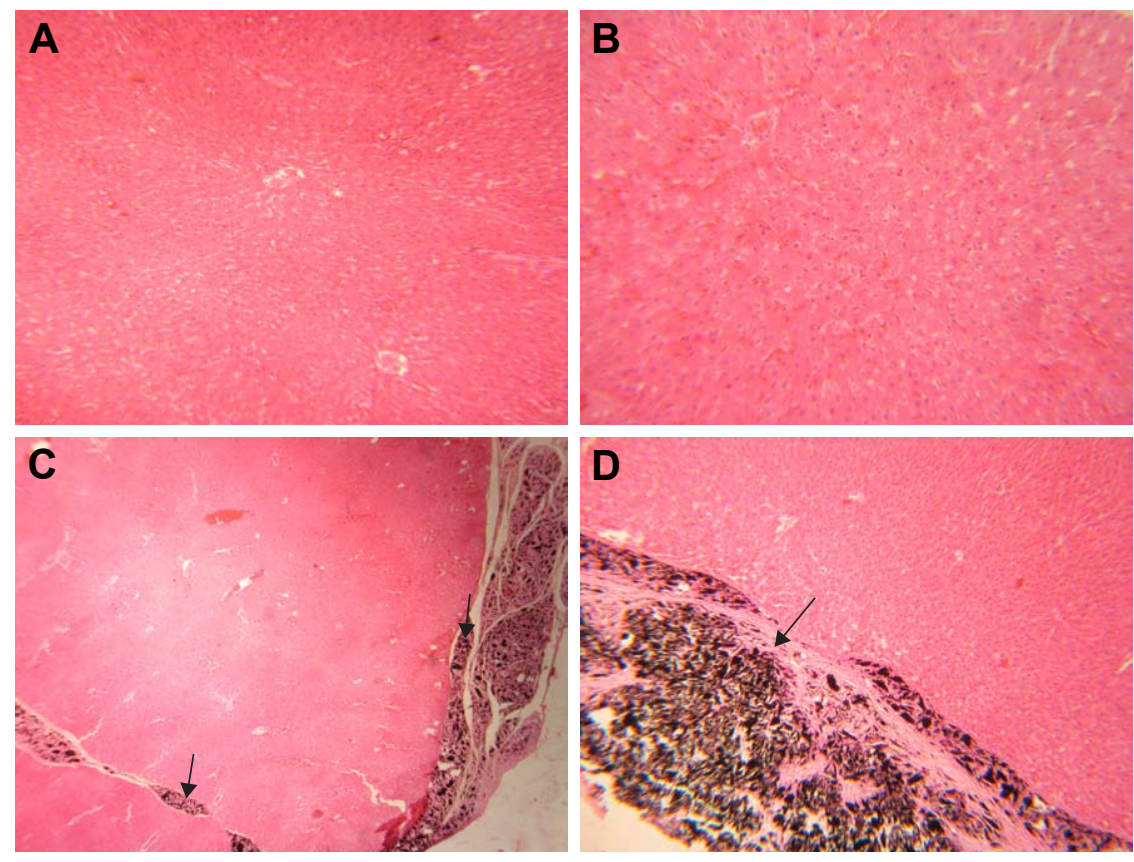

Figure 3 Histopathological effects of GONs on the liver of rats after 21 days. Representative photomicrograph of (A) control rats (H\&E, $\times 100)$, (B) rats receiving $50 \mathrm{mg} / \mathrm{kg}$ of GONs (H\&E, $\times 100$ ), (C) rats receiving $150 \mathrm{mg} / \mathrm{kg}$ of GONs (H\&E, $\times 100$ ), and (D) rats receiving $500 \mathrm{mg} / \mathrm{kg}$ of GONs (H\&E, $\times 100$ ).

Note: Black arrows indicate the accumulation of GONs.

Abbreviations: GONs, graphene oxide nanoplatelets; H\&E, hematoxylin and eosin.

In the present study, we evaluated the toxicity of GO, which was characterized as nanoplatelet morphology (GONs) with an average number of 3-6 layers, thickness of $0.8-2 \mathrm{~nm}$, and lateral dimension of $5-10 \mu \mathrm{m}$ after injecting into adult male Wistar rats. The animals were exposed to four doses of 50,150 , or $500 \mathrm{mg} / \mathrm{kg}$ GONs by intraperitoneal injections during 1 week and then allowed 2 weeks to recover. According to the results (Figure 2 and Table 2), it can be
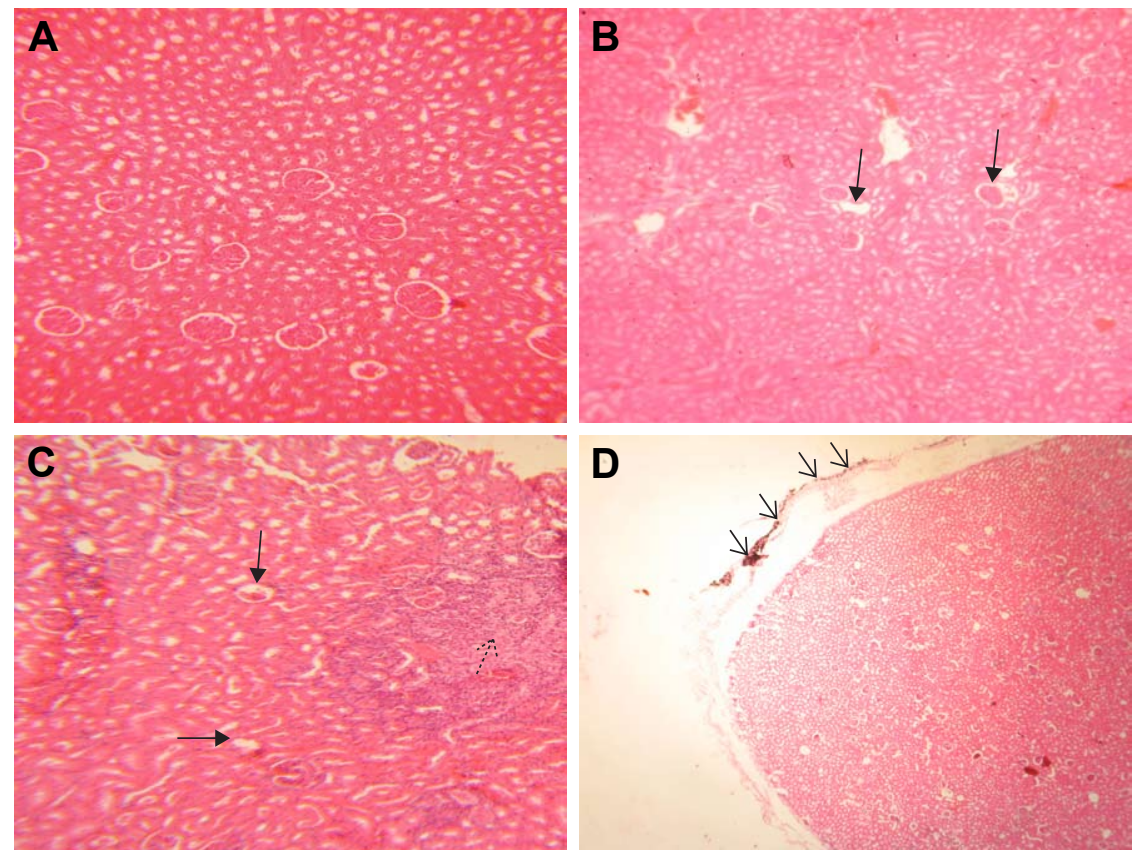

Figure 4 Histopathological effects of GONs on the kidney of rats after 2 I days. Representative photomicrograph of $(\mathbf{A})$ control group $(\mathrm{H \& E}, \times 200)$, (B) rats receiving $50 \mathrm{mg} / \mathrm{kg}$ of GONs (H\&E, $\times 100)$; (C) rats receiving $150 \mathrm{mg} / \mathrm{kg}$ of GONs (H\&E, $\times 100)$, and (D) rats receiving $500 \mathrm{mg} / \mathrm{kg}$ of GONs (H\&E, $\times 40)$.

Notes: Black arrows indicate glomerular atrophy, A black dashed-arrow indicates interstitial nephritis, Black small arrows indicate capsular accumulation of GONs.

Abbreviations: GONs, graphene oxide nanoplatelets; H\&E, hematoxylin and eosin. 

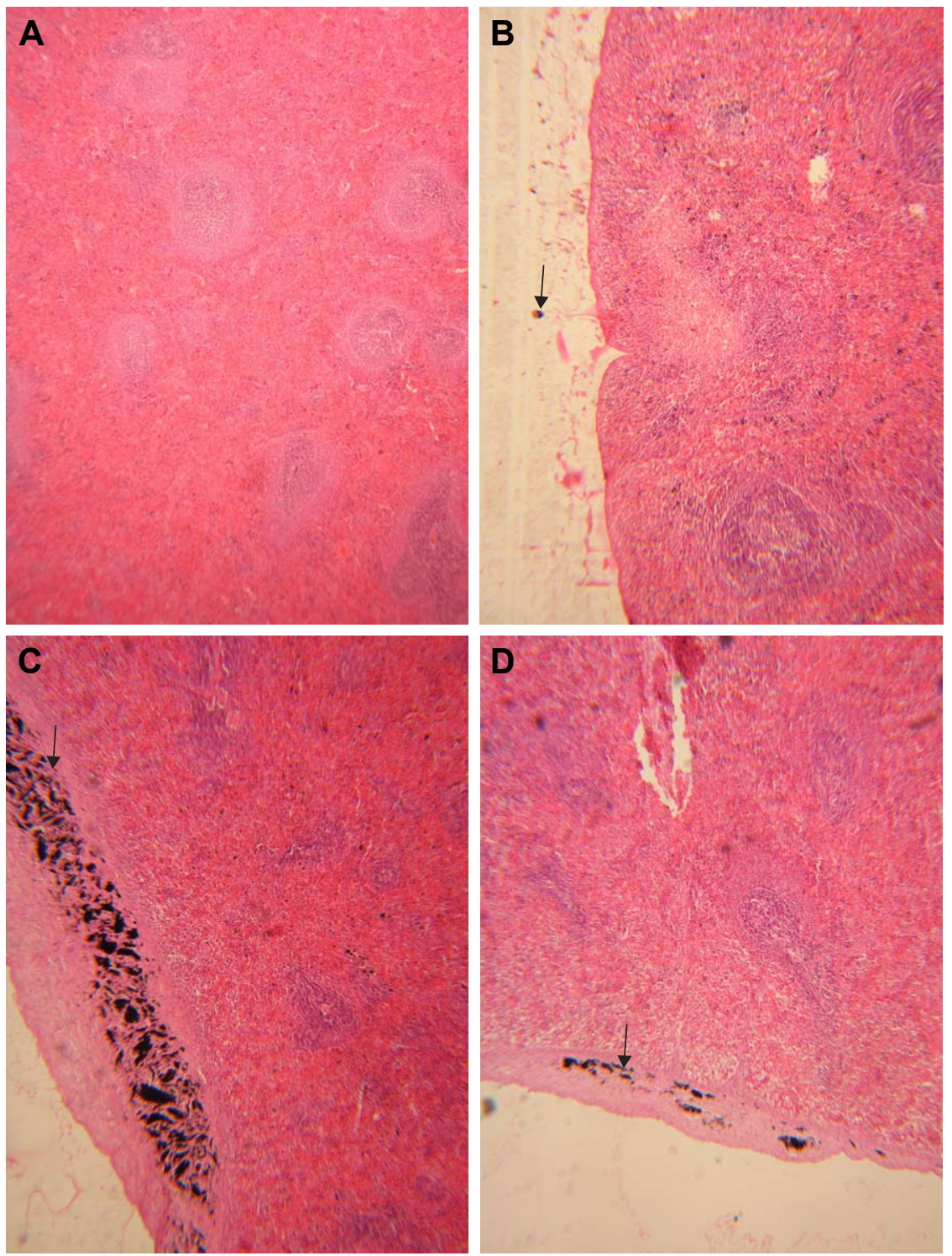

Figure 5 Histopathological effects of GONs on the spleen of rats after 21 days. Representative photomicrograph of $(\mathbf{A})$ control group $(\mathrm{H} \& \mathrm{E}, \times 100)$, (B) rats receiving $50 \mathrm{mg} / \mathrm{kg}$ of GONs (H\&E, $\times 100)$, (C) rats receiving $150 \mathrm{mg} / \mathrm{kg}$ of GONs (H\&E, $\times 100)$, and (D) rats receiving $500 \mathrm{mg} / \mathrm{kg}$ of GONs $(\mathrm{H} \& \mathrm{E}, \times 100)$.

Note: Black arrows indicate the accumulation of GONs.

Abbreviations: GONs, graphene oxide nanoplatelets; H\&E, hematoxylin and eosin.

concluded that four cumulative doses of $50(200 \mathrm{mg} / \mathrm{kg})$ or $150 \mathrm{mg} / \mathrm{kg}(600 \mathrm{mg} / \mathrm{kg})$ GONs did not affect the body weights of animals or blood and serum parameters after 21 days. On the contrary, GONs at four cumulative doses of $500 \mathrm{mg} / \mathrm{kg}(2 \mathrm{~g} / \mathrm{kg})$ hindered body weight gain and induced a significant increase in serum level of TB and a significant decrease in serum levels of TG and HDL after 21 days (Table 2 and Figure 2).

Histopathological findings showed that GONs induced dose-dependent injuries in the liver, kidney, spleen, lung, intestine, and brain after 21 days (Figures 3-8).

In the livers, sinusoidal injury, hyperemia, accumulation of GONs in the capsular regions, perivascular infiltration, and granulomatous reaction were observed. In the kidneys, there was GONs accumulation at the capsular regions, hyperemia, interstitial nephritis, glomerular atrophy, and granulomatous reaction. In the spleens, we observed capsular thickening, capsular accumulation of particles, and hemosiderosis. In the lungs, there was alveolar wall thickening along with inflammation, hemosiderosis, and hyperemia. In the intestines, there were serosa thickening, accumulation of GONs, and giant cell formation. In the brains, there were some neuronal cell degenerations and necrosis.

The present results are in agreement with the study of $\mathrm{Li}$ et $\mathrm{al}^{31}$ showing that the injection of GO into male Sprague Dawley rats caused no significant changes in the 

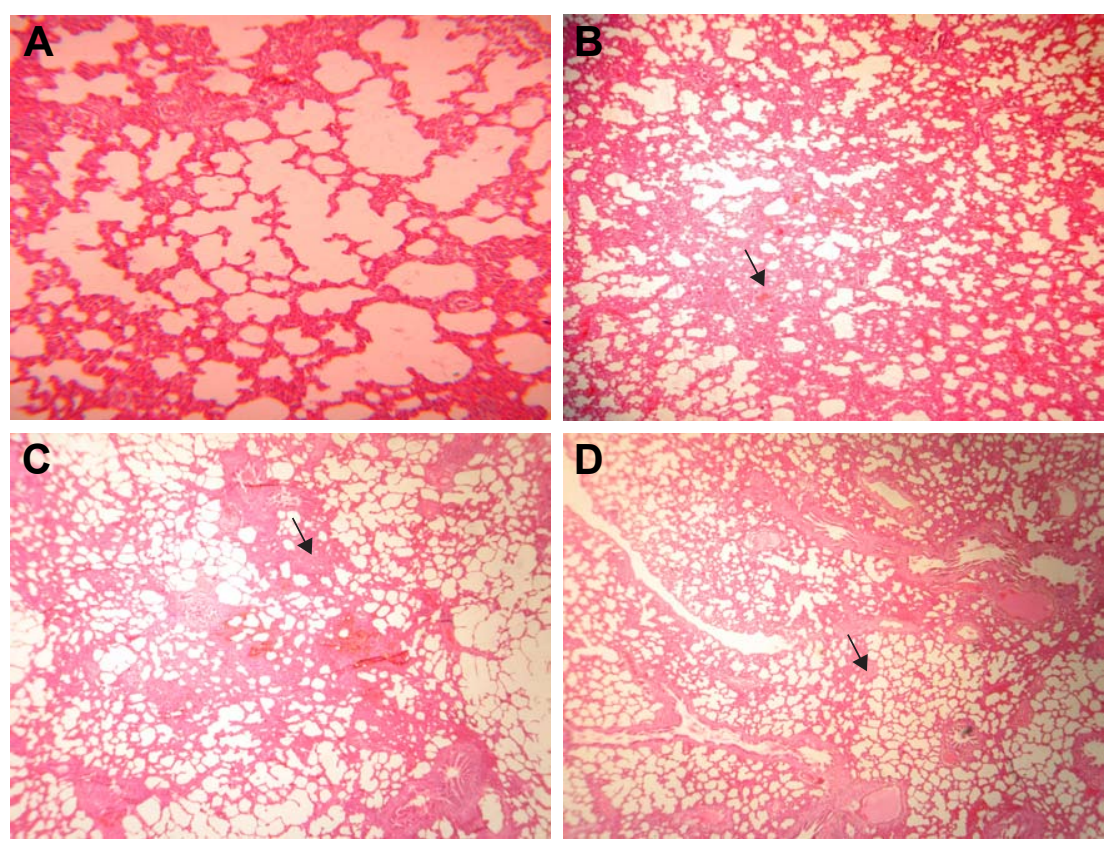

Figure 6 Histopathological effects of GONs on the lung of rats after 21 days. Representative photomicrograph of $(\mathbf{A})$ control group (H\&E, $\times 100)$, (B) rats receiving $50 \mathrm{mg} / \mathrm{kg}$ of GONs (H\&E, $\times 40)$, (C) rats receiving $150 \mathrm{mg} / \mathrm{kg}$ of GONs (H\&E, $\times 40)$, and (D) rats receiving $500 \mathrm{mg} / \mathrm{kg}$ of GONs (H\&E, $\times 40)$.

Note: Small black arrows indicate alveolar wall thickening.

Abbreviations: GONs, graphene oxide nanoplatelets; H\&E, hematoxylin and eosin.

hematological parameters, but induced a significant decrease in serum levels of lipid profiles including HDL. Also, they found that GO induced hyperemia and alveolar wall thickening in the lung, hyperemia and sinusoidal injury in the liver, accumulation of GO and hyperemia in the spleen, and no morphological changes in the heart, which is consistent with our histopathological findings. Another study disclosed the dose-dependent histopathological changes in the kidney of
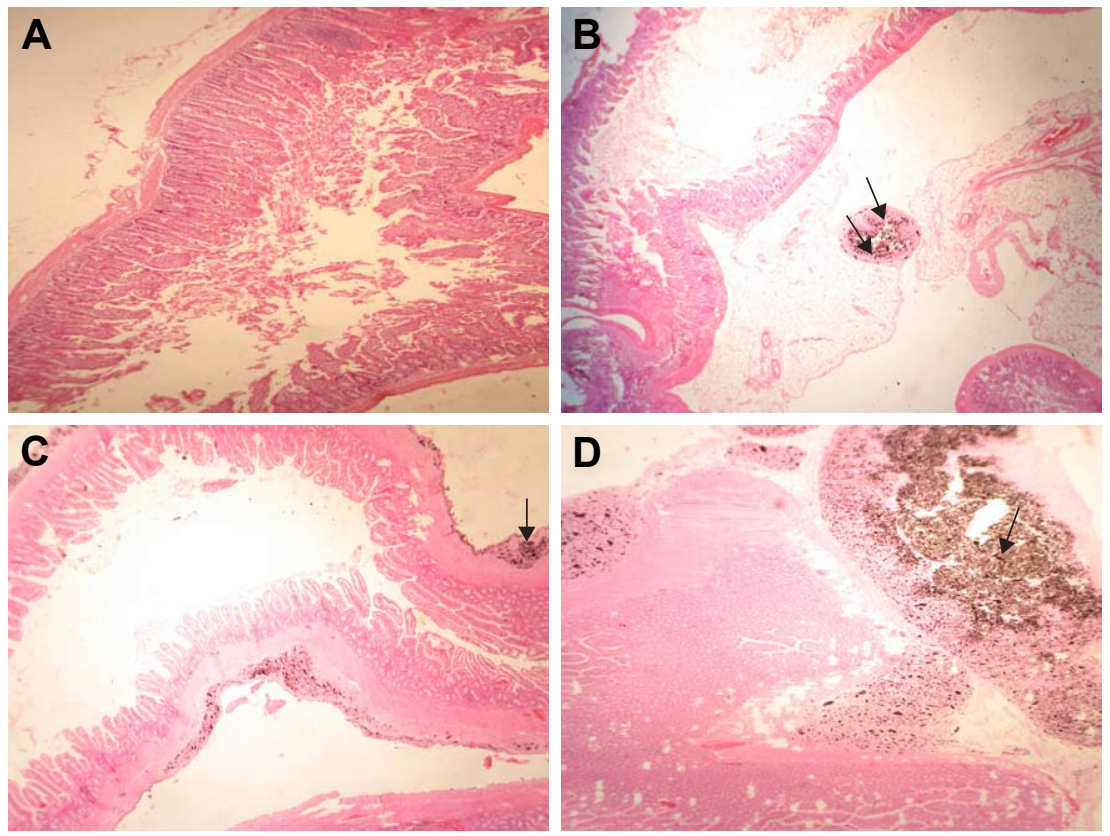

Figure 7 Histopathological effects of GONs on the intestine of rats after 21 days. Representative photomicrograph of $(\mathbf{A})$ control group $(\mathrm{H} \& \mathrm{E}, \times 100)$, (B) rats receiving $50 \mathrm{mg} / \mathrm{kg}$ of GONs (H\&E, $\times 100)$; (C) rats receiving $150 \mathrm{mg} / \mathrm{kg}$ of GONs (H\&E, $\times 100)$; and (D) rats receiving $500 \mathrm{mg} / \mathrm{kg}$ of GONs show a high accumulation of GONs in the intestinal tissue $(\mathrm{H} \& \mathrm{E}, \times 40)$.

Notes: Black arrows indicate GONs accumulation; small black arrows indicate accumulation of GONs in the adventitia layer.

Abbreviations: GONs, graphene oxide nanoplatelets; H\&E, hematoxylin and eosin. 

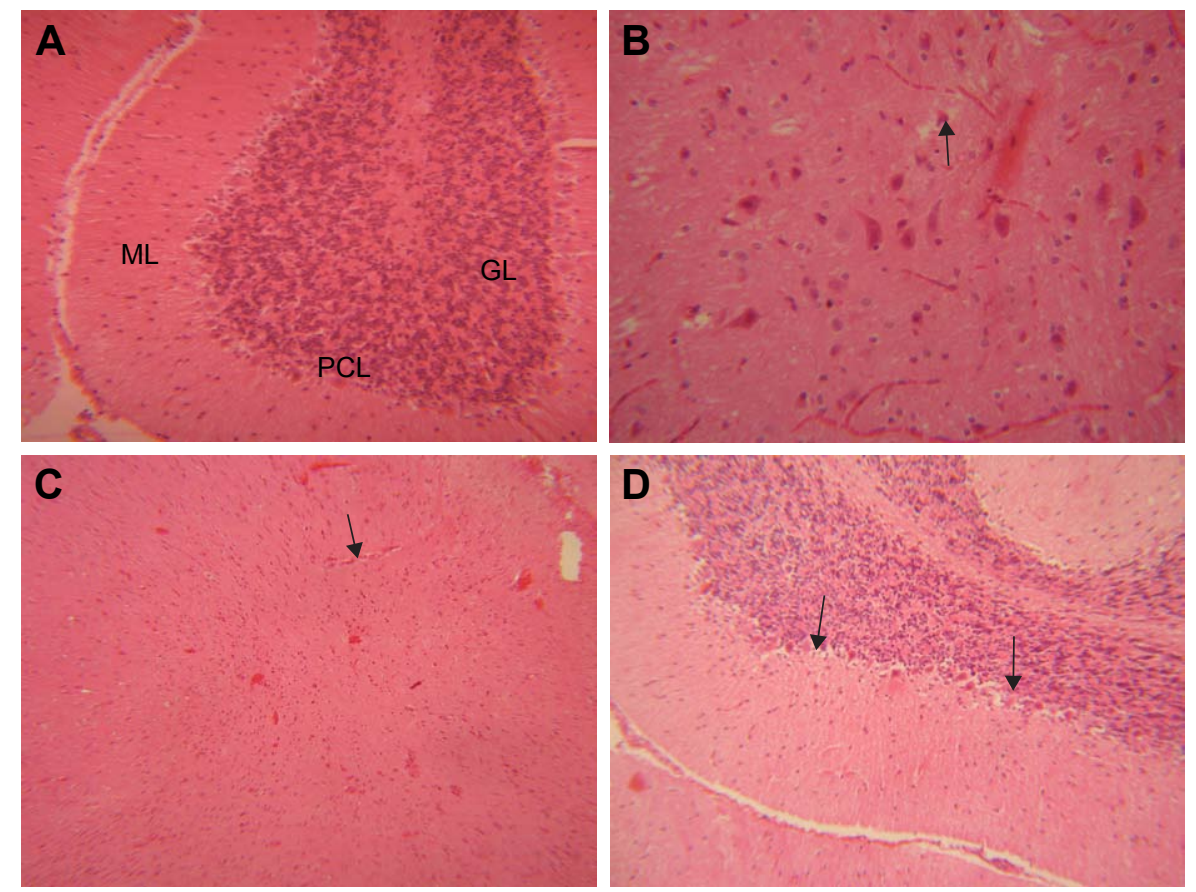

Figure 8 Histopathological effects of GONs on the brain of rats after 21 days. Representative photomicrograph of $(\mathbf{A})$ control group $($ section of cerebellum, H\&E, $\times 200)$, (B) rats receiving $50 \mathrm{mg} / \mathrm{kg}$ of GONs (section of cerebrum, H\&E, $\times 400$ ), (C) rats receiving I50 mg/kg of GONs (section of cerebrum, H\&E, $\times 100$ ), and (D) rats receiving $500 \mathrm{mg} / \mathrm{kg}$ of GONs (section of cerebellum, H\&E, $\times 100$ ).

Note: Black arrows indicate degenerated Purkinje cells in cerebellum; small black arrows indicate degenerated neuronal cells in cerebrum.

Abbreviations: ML, molecular layer; PCL, Purkinje cell layer; GL, granular layer; GONs, graphene oxide nanoplatelets; H\&E, hematoxylin and eosin.

male Sprague Dawley rats upon exposure to different doses of GO..$^{32}$ This report further confirmed our dose-dependent histopathological findings in the kidney of animals upon exposure to GONs.

In vivo studies on mice as an animal model also showed similar results that are consistent with the present study. For example, Wang et $\mathrm{al}^{33}$ reported the dose-dependent toxicity of GO on mice. GO did not demonstrate any obvious clinical signs of toxicity, including body weight change, in low doses, but showed body weight loss and histopathological changes in high doses. GO caused inflammation and histopathological changes in the lung, liver, spleen, and kidney in a dosedependent manner. Their report revealed that, by increasing the dose, GO could induce inflammatory responses, including a granulomatous reaction following particle accumulations in internal organs. Previous reports showed that the liver, lung, spleen, and kidney, but not the heart, were among the main target organs for GO toxicity. ${ }^{34,35}$

In the current study, GONs also accumulated in the serosa of intestinal tissue. The study conducted by Kurantowicz et $\mathrm{a}^{36}$ revealed that $\mathrm{GO}$ after intraperitoneal injections in rats formed aggregates in the stomach serous membrane, among mesentery, and in near distance to spleen serosa. However, GO caused no pathological changes in the kidney, lungs, heart, spleen, and liver, and had no effect on the animal weight, biochemical, or hematological parameters during 4 weeks of exposure. They suggested the good biocompatibility of GO, despite the foreign body non-biodegradable behavior of it in rats. The discrepancy between their report and our study is largely due to the differences between GO characteristics, concentration, and experimental design across two studies. Another determinant factor in the biocompatibility and potential toxicity of GO is the existence of functionalization. It has been reported that GONs with dextran functionalization had no effects on hematological indices, serum biochemical parameters, and histopathology of Wistar rats at doses under $125 \mathrm{mg} / \mathrm{kg}$. However, this formulation resulted in minor morphological changes in the liver, lung, spleen, and kidney at doses $\geq 250 \mathrm{mg} / \mathrm{kg}$. The general patterns of these changes included mild focal congestions, along with particle aggregations. ${ }^{30}$

Several studies reported that GO with polyethylene glycol (PEG) functionalization mitigate the toxicity. In fact, GO functionalized with PEG had less toxic effects on the hematology, serum biochemistry, and histopathology, despite observing its biodistribution in internal organs including liver, lung, kidney, and spleen. ${ }^{37,38}$

Our results demonstrated that GONs induced neurotoxic effects in rats. A study by Shang et $\mathrm{al}^{39}$ showed that intraperitoneal injection of GO in male BALB/c mice at a dose of 
$4 \mathrm{mg} / \mathrm{kg}$ for seven consecutive days caused brain damage. The mechanism of this neurotoxicity has been proposed through the lipid peroxidation of the membrane, following excessive generation of reactive oxygen species (ROS) induced by $\mathrm{GO}$, and subsequent overwhelming of antioxidant defenses of cells.

It has been widely accepted that one of the main mechanisms of toxicity of GNMs, including GO, is the generation of intracellular ROS that cause damage to cell macromolecules, including membrane phospholipids, proteins, and DNA, triggering molecular pathways of apoptotic or necrotic cell death. ${ }^{40-42}$

In the present study, the common finding among the internal organs was inflammatory response, including granulomatous reaction as a consequence of GONs accumulations. Interestingly, it has been shown that GO can activate cell surface toll-like receptors (TLR4 and TLR9) and induce proinflammatory pathways involving NF- $\kappa B$ that ultimately give rise to the production and secretion of cytokines and chemokines. ${ }^{43}$ Systemic delivery of GO caused significant production of inflammatory cytokines IL- 6 and TNF- $\alpha$ in lavage fluids and serum in mice. ${ }^{44}$

Physical contact of GNMs including GO with cell membranes was reported as another mechanism of toxicity. The experiment by $\mathrm{Li}$ et $\mathrm{al}^{45}$ showed that graphene flakes as large as $0.5-10 \mu \mathrm{m}$ in lateral dimensions entered cells by spontaneous membrane infiltration at corner sites and edge asperities. Otherwise, it has been shown that GO caused ROS generation and subsequent toxicity by accumulating on the cell surface without internalization. ${ }^{46} \mathrm{GO}$ can interact with the cytoskeletal components of the cell, perturbing membrane integrity and inducing cell-cycle alterations, apoptosis, and oxidative stress. ${ }^{47} \mathrm{GO}$ can also cause mitochondrial damage, including the decrease in mitochondrial membrane potential, reduction of ATP production, dysregulation of $\mathrm{Ca}^{2+}$ homeostasis, interference with electron transport chain by disturbing electron transfer, and overproduction of ROS. ${ }^{48,49}$ The quantitative proteomics approach proposed that GO can interfere with multiple pathways involved in cell energy production and metabolism. ${ }^{50}$

We acknowledge that the current study has not provided the data regarding the molecular mechanism of toxic injuries of GO including oxidative stress, inflammation, or autophagy. Thus, further investigations are desirable to explore the molecular mechanisms of toxicities of GO.

Another limitation of the present study is the fact that the data was obtained using Wistar rats as an in vivo animal model. Thus, we can not guarantee similar results when other in vivo rodent animal models are used, even by conducting a similar study protocol and using the same characterized GO. In addition, utilization of other in vivo mammalian animal models, especially non-rodents, are required to vet the preclinical safety assessment of GO.

Nonetheless, our results, especially the histopathological findings, can be used for recognizing the characters of toxic injuries of GO on different organs and setting the stage for future investigations on their tissue-specific mechanisms of toxic injuries through considering the abovementioned molecular mechanisms or new ones. Also, the present results are important for safety profiling of the studied GO and, since it showed toxicity, it is suggested not to be considered for clinical applications without taking further actions to reduce its toxicity. It will be interesting to functionalize it with biocompatible coatings and compare its toxicological study results with the present study. Nonetheless, using other GOs with different characteristics, in particular, functionalized GOs are proposed to evaluate for potential toxicity before being considered as promising nanomaterials of clinical applications.

\section{Conclusion}

The present study demonstrated the toxicity of GONs with respect to the body weight, biochemical, and histopathological changes following repeated intraperitoneal injections of the nanoparticles in the Wistar rats. GONs at four cumulative doses of $500 \mathrm{mg} / \mathrm{kg}$ prevented a significant gain in the body weight of animals over a 21 days period. GONs at this dose level caused a significant increase in serum level of TB, with a significant decrease in the serum levels of TG and HDL over the same period. According to our histopathological findings, it can be concluded that GONs were toxic for the liver, kidney, spleen, lung, intestine, and brain, but not the heart. In general, GONs induced inflammation and a granulomatous reaction in a dose-dependent manner after accumulating inside the body. Our findings can be a useful avenue for further studies to explore the tissue-specific molecular mechanisms of toxicities of GO. The GO is the superior material on the planet and will find many applications in biomedicine. Therefore, uniform strategies for mitigating the toxicity of GOs such as functionalization are encouraged in order to speed up its application to the clinical setting.

\section{Disclosure}

This study is a part of Mohammad Amrollahi-Sharifabadi's $\mathrm{PhD}$ thesis. The authors report no conflicts of interest in this work. 


\section{References}

1. Novoselov KS, Geim AK, Morozov SV, et al. Electric field effect in atomically thin carbon films. Science. 2004;306(5696):666-669.

2. Nezakati T, Seifalian A, Tan A, Seifalian AM. Conductive polymers: opportunities and challenges in biomedical applications. Chem Rev. 2018;118(14):6766-6843.

3. Allen MJ, Tung VC, Kaner RB. Honeycomb carbon: a review of graphene. Chem Rev. 2010;110(1):132-145.

4. Avouris P, Dimitrakopoulos C. Graphene: synthesis and applications. Mater Today. 2012;15(3):86-97.

5. Geim AK, Novoselov KS. The rise of graphene. Nat Mater. 2007;6(3): 183-191.

6. Subrahmanyam KS, Panchakarla LS, Govindaraj A, Rao CNR. Simple Method of Preparing Graphene Flakes by an Arc-Discharge Method. The Journal of Physical Chemistry C. 2009;113(11):4257-4259.

7. Terrones M, Botello-Méndez AR, Campos-Delgado J, et al. Graphene and graphite nanoribbons: Morphology, properties, synthesis, defects and applications. Nano Today. 2010;5(4):351-372.

8. Schinwald A, Murphy FA, Jones A, Macnee W, Donaldson K. Graphenebased nanoplatelets: a new risk to the respiratory system as a consequence of their unusual aerodynamic properties. ACS Nano. 2012;6(1): 736-746.

9. Kosynkin DV, Higginbotham AL, Sinitskii A, et al. Longitudinal unzipping of carbon nanotubes to form graphene nanoribbons. Nature. 2009;458(7240):872-876.

10. Chong Y, Ma Y, Shen $\mathrm{H}$, et al. The in vitro and in vivo toxicity of graphene quantum dots. Biomaterials. 2014;35(19):5041-5048.

11. Efremova LV, Vasilchenko AS, Rakov EG, Deryabin DG. Toxicity of graphene shells, graphene oxide, and graphene oxide paper evaluated with Escherichia coli biotests. Biomed Res Int. 2015; Article ID 869361.

12. Nezakati T, Cousins BG, Seifalian AM. Toxicology of chemically modified graphene-based materials for medical application. Arch Toxicol. 2014;88(11):1987-2012.

13. Sawosz E, Jaworski S, Kutwin M, et al. Toxicity of pristine graphene in experiments in a chicken embryo model. Int J Nanomedicine. 2014;9: 3913-3922.

14. Gurunathan S, Han JW, Park JH, Eppakayala V, Kim JH. Ginkgo biloba: a natural reducing agent for the synthesis of cytocompatible graphene. Int J Nanomedicine. 2014;9:363-377.

15. Suvarnaphaet P, Pechprasarn S, Suejit Pechprasarn. Graphene-Based Materials for Biosensors: A Review. Sensors. 2017;17(10):2161.

16. Liu J, Cui L, Losic D. Graphene and graphene oxide as new nanocarriers for drug delivery applications. Acta Biomater. 2013;9(12): 9243-9257.

17. Chang Y, Yang ST, Liu JH, et al. In vitro toxicity evaluation of graphene oxide on A549 cells. Toxicol Lett. 2011;200(3):201-210.

18. Bengtson S, Kling K, Madsen AM, et al. No cytotoxicity or genotoxicity of graphene and graphene oxide in murine lung epithelial FE1 cells in vitro. Environ Mol Mutagen. 2016;57(6):469-482.

19. Liu Y, Luo Y, Wu J, et al. Graphene oxide can induce in vitro and in vivo mutagenesis. Sci Rep. 2013;3:3469.

20. Pelin M, Fusco L, León V, et al. Differential cytotoxic effects of graphene and graphene oxide on skin keratinocytes. Sci Rep. 2017; 7:40572.

21. Zhang X, Yin J, Peng C, et al. Distribution and biocompatibility studies of graphene oxide in mice after intravenous administration. Carbon. 2011;49(3):986-995.

22. Chng EL, Chua CK, Pumera M. Graphene oxide nanoribbons exhibit significantly greater toxicity than graphene oxide nanoplatelets. Nanoscale. 2014;6(18):10792-10797.

23. Talukdar Y, Rashkow J, Lalwani G, Kanakia S, Sitharaman B. The effects of graphene nanostructures on mesenchymal stem cells. Biomaterials. 2014;35(18):4863-4877.

24. Liu JH, Yang ST, Wang H, et al. Effect of size and dose on the biodistribution of graphene oxide in mice. Nanomedicine. 2012;7(12): 1801-1812.
25. Liu S, Hu M, Zeng $\mathrm{TH}$, et al. Lateral dimension-dependent antibacterial activity of graphene oxide sheets. Langmuir. 2012;28(33): 12364-12372.

26. Vallabani NV, Mittal S, Shukla RK, et al. Toxicity of graphene in normal human lung cells (BEAS-2B). J Biomed Nanotechnol. 2011;7(1): 106-107.

27. Wang A, Pu K, Dong B, et al. Role of surface charge and oxidative stress in cytotoxicity and genotoxicity of graphene oxide towards human lung fibroblast cells. J Appl Toxicol. 2013;33(10):1156-1164.

28. Ema M, Gamo M, Honda K. A review of toxicity studies on graphenebased nanomaterials in laboratory animals. Regul Toxicol Pharmacol. 2017;85:7-24.

29. Nezakati T, Tan A, Seifalian AM. Enhancing the electrical conductivity of a hybrid POSS-PCL/graphene nanocomposite polymer. J Colloid Interface Sci. 2014;435:145-155.

30. Kanakia S, Toussaint JD, Mullick Chowdhury S, et al. Dose ranging, expanded acute toxicity and safety pharmacology studies for intravenously administered functionalized graphene nanoparticle formulations. Biomaterials. 2014;35(25):7022-7031.

31. Li Y, Wang Y, Tu L, et al. Sub-acute toxicity study of graphene oxide in the Sprague-Dawley rat. Int J Environ Res Public Health. 2016; 13(11): 1149 .

32. Patlolla AK, Randolph J, Kumari SA, Tchounwou PB. Toxicity evaluation of graphene oxide in kidneys of Sprague-Dawley rats. Int J Environ Res Public Health. 2016;13(4):380.

33. Wang K, Ruan J, Song H, et al. Biocompatibility of graphene oxide. Nano scale Res Lett. 2011;6(1):8.

34. Syama S, Paul W, Sabareeswaran A, Mohanan PV. Raman spectroscopy for the detection of organ distribution and clearance of PEGylated reduced graphene oxide and biological consequences. Biomaterials. 2017;131: $121-130$.

35. Jasim DA, Ménard-Moyon C, Bégin D, Bianco A, Kostarelos K. Tissue distribution and urinary excretion of intravenously administered chemically functionalized graphene oxide sheets. Chem Sci. 2015;6(7): 3952-3964.

36. Kurantowicz N, Strojny B, Sawosz E, et al. Biodistribution of a high dose of diamond, graphite, and graphene oxide nanoparticles after multiple intraperitoneal injections in rats. Nanoscale Res Lett. 2015; 10:398.

37. Yang K, Gong H, Shi X, et al. In vivo biodistribution and toxicology of functionalized nano-graphene oxide in mice after oral and intraperitoneal administration. Biomaterials. 2013;34(11):2787-2795.

38. Li B, Zhang XY, Yang JZ, et al. Influence of polyethylene glycol coating on biodistribution and toxicity of nanoscale graphene oxide in mice after intravenous injection. Int J Nanomedicine. 2014;9: 4697-4707.

39. Shang S, Yang S-Y, Liu Z-M, Yang X. Oxidative damage in the kidney and brain of mice induced by different nano-materials. Front Biol. 2015; 10(1):91-96.

40. Ma Y, Shen H, Tu X, Zhang Z. Assessing in vivo toxicity of graphene materials: current methods and future outlook. Nanomedicine. 2014; 9(10):1565-1580.

41. Sasidharan A, Panchakarla LS, Chandran P, et al. Differential nanobio interactions and toxicity effects of pristine versus functionalized graphene. Nanoscale. 2011;3(6):2461-2464.

42. Zhang W, Wang C, Li Z, et al. Unraveling stress-induced toxicity properties of graphene oxide and the underlying mechanism. Adv Mater. 2012;24(39):5391-5397.

43. Chen GY, Yang HJ, Lu CH, Ch L, et al. Simultaneous induction of autophagy and toll-like receptor signaling pathways by graphene oxide. Biomaterials. 2012;33(27):6559-6569.

44. Ma J, Liu R, Wang X, et al. Crucial role of lateral size for graphene oxide in activating macrophages and stimulating pro-inflammatory responses in cells and animals. ACS Nano. 2015;9(10):10498-10515.

45. Li Y, Yuan H, von dem Bussche A, et al. Graphene microsheets enter cells through spontaneous membrane penetration at edge asperities and corner sites. Proc Natl Acad Sci U S A. 2013;110(30):12295-12300. 
46. Chatterjee N, Eom HJ, Choi J. A systems toxicology approach to the surface functionality control of graphene-cell interactions. Biomaterials. 2014;35(4):1109-1127.

47. Matesanz MC, Vila M, Feito MJ, et al. The effects of graphene oxide nanosheets localized on F-actin filaments on cell-cycle alterations. Biomaterials. 2013;34(5):1562-1569.

48. Lammel T, Boisseaux P, Fernández-Cruz ML, Navas JM. Internalization and cytotoxicity of graphene oxide and carboxyl graphene nanoplatelets in the human hepatocellular carcinoma cell line Hep G2. Part Fibre Toxicol. 2013;10:27.
49. Duch MC, Budinger GR, Liang YT, et al. Minimizing oxidation and stable nanoscale dispersion improves the biocompatibility of graphene in the lung. Nano Lett. 2011;11(12):5201-5207.

50. Zhou T, Zhang B, Wei P, et al. Energy metabolism analysis reveals the mechanism of inhibition of breast cancer cell metastasis by PEG-modified graphene oxide nanosheets. Biomaterials. 2014;35(37):9833-9843.
International Journal of Nanomedicine

\section{Publish your work in this journal}

The International Journal of Nanomedicine is an international, peerreviewed journal focusing on the application of nanotechnology in diagnostics, therapeutics, and drug delivery systems throughout the biomedical field. This journal is indexed on PubMed Central, MedLine, CAS, SciSearch $®$, Current Contents ${ } /$ Clinical Medicine,

\section{Dovepress}

Journal Citation Reports/Science Edition, EMBase, Scopus and the Elsevier Bibliographic databases. The manuscript management system is completely online and includes a very quick and fair peer-review system, which is all easy to use. Visit http://www.dovepress.com/ testimonials.php to read real quotes from published authors.

Submit your manuscript here: http://www.dovepress.com/international-journal-of-nanomedicine-journal 